\title{
Understanding the Effects of Age and T-Cell Differentiation on COVID-19 Severity: Implicating a Fas/FasL- mediated Feed-Forward Controller of T-Cell Differentiation
}

\author{
Anthony J. Leonardi ${ }^{1 *}$, Christos P. Argyropoulos ${ }^{2}$, Adam Hamdy $^{3}$ and Rui B. Proenca ${ }^{4}$ \\ ${ }^{1}$ Environmental Health and Engineering, Johns Hopkins Bloomberg School of Public Health, Baltimore, MD, United States, \\ 2 Department of Internal Medicine, Division of Nephrology, University of New Mexico School of Medicine, Albuquerque, \\ NM, United States, ${ }^{3}$ Independent Researcher, Port Louis, Mauritius, ${ }^{4}$ Department of Biology, Johns Hopkins University, \\ Baltimore, MD, United States
}

Keywords: Fas, CD8, T cells, differentiation, paracrine, FasL, SARS-CoV-2, feed-forward Loop

\section{OPEN ACCESS}

Edited by:

Loretta Tuosto,

Sapienza University of Rome, Italy

Reviewed by: Giovanna Borsellino,

Santa Lucia Foundation (IRCCS), Italy

*Correspondence:

Anthony J. Leonardi aleona10@jhmi.edu

Specialty section: This article was submitted to

T Cell Biology,

a section of the journal

Frontiers in Immunology

Received: 12 January 2022

Accepted: 11 February 2022

Published: 03 March 2022

Citation:

Leonardi AJ, Argyropoulos CP,

Hamdy A and Proenca RB (2022)

Understanding the Effects of Age and

T-Cell Differentiation on COVID-19

Severity: Implicating a Fas/FasLmediated Feed-Forward Controller of

$T$-Cell Differentiation.

Front. Immunol. 13:853606. doi: 10.3389/fimmu.2022.853606

\section{INTRODUCTION}

Feed-forward loops are means of managing homeostasis under dynamic conditions (1-4). It is a way for organisms and cells to manage inputs and responses while maintaining optimal functioning (1).

Feed-forward control differs from feedback control in a number of ways, including how a feedforward controller is 1) responsive to process parameter changes in the system and 2) corrects for disturbances in the system (4). While the more widely known feedback systems track a continuous measurement ("an error signal") and attempt to correct it by matching their "control signals", feedforward systems are command and control: once the control signal has been issued, it cannot be adjusted until a new control signal has been issued.

An example will make the distinction between these two forms of control clearer. While driving, slowing down before making a turn is a form of feed forward control, because the driver ("controller") anticipates the effects of inertia upon the moving car and attempts to pre-compensate. Adaptive cruise control offers an example of a feedback system: the car's "computers" continuously measures the speed of the car and either accelerates or decelerates to keep the speed constant at the desired level. In this analogy, the Fas and FasL expression induced following stimulation (5) are the 'control' signals, and the ensuing differentiation, cytotoxic acquisition, and apoptosis via Fas (which can terminate in effector function and death) is the 'turning' maneuver. The maneuver (turning vs. differentiation with death or effector function) has a preparation stage that depends on the 'speed' (which is the differentiation state of the T-cells in the pool).

Feed-forward loops (FFLs) are common in physiological systems and immunological responses $(1,2,6,7)$. For example, the mTORC1/Akt axis has been shown to be regulated in a feed-forward manner, and a feed-forward inflammatory loop has been implicated in lethal influenza $(7,8)$. Notably, the Akt pathway has been shown to be the predominant pathway controlling $\mathrm{T}$ cell memory and effector differentiation (9). Illustrating its importance for T-cell effector function, the inhibition of this pathway following stimulation uncouples $\mathrm{T}$ cell differentiation and proliferation following $\mathrm{T}$ cell stimulation and keeps $\mathrm{t}$ cells in the memory state $(10,11)$. 
$\mathrm{T}$ cells can exert a contact-dependent paracrine Fas-FasL mediated differentiation effect on co-stimulated $\mathrm{T}$ cells in vivo and in vitro $(5,12,13)$ with directionality from the FasLexpressing memory and effector cells to the Fas-expressing naïve $\mathrm{T}$ cells and other memory/effector cells. Following stimulation but before differentiation occurs, a non-apoptotic Fas (CD95) signal travels through the Akt pathway in order to differentiate T-cells. Illustrating this, Fas blockade in a pool of $\mathrm{T}$ cells following stimulation in vitro also uncouples differentiation and proliferation of $\mathrm{T}$ cells and prevents their terminal effector differentiation and release of effector cytokines. This means the canonical death receptor CD95 is involved in the function and fate of $\mathrm{T}$ cells in a pool. This behavior of T-T interactions which influence the acquisition of effector function represents quorum decision-making for differentiation, cytotoxicity, and apoptosis, all via Fas, implying $\mathrm{T}$ cells behave as a highly regulated quorum sensing tissue that relies on its homotypic immediate environment for context (14).

Typically, feed-forward control is described in a single cell, but since $T$ cells are able to cause the differentiation of paracrine $\mathrm{T}$ cells and also 'soak up' like a cytokine sink or withhold differentiation of paracrine $\mathrm{T}$ cells, they are able to act as a quorum (Figures 1A-C) (5). In this sense, a single cell with a given phenotype, such as an activated naive or Tscm CD8 T cell expressing CD95 for example, is able to inhibit effector differentiation of adjacent memory cells by 'soaking up' or acting as a 'sink' for CD95L, for example.

That is the first component of the feed-forward loop we describe in Figure 1D. The second component of the loop are the effector cells (in red) that highly express both CD95 and CD95L and will agonize adjacent cells and bring about their differentiation and subsequent death, which is limited to terminally differentiated effectors (5). By terminating the FFL with apoptosis in those cells which are terminally differentiated and therefore have high effector function, this allows for selflimiting effector responses.

However, the naive and Tscm cells will prevent this from occurring when they are present, by virtue of 'soaking up' this CD95L signal (5). The sum of this interaction comprises a feedforward loop (Figure 1D). This interaction we believe is a method in control in the balance of $\mathrm{T}$ cell homeostasis between the blood, lymphoid organs, and peripheral tissues.

In lethal cases of Covid-19 there is a necrosis of the spleen and lymph nodes perhaps indicative of excessive $\mathrm{T}$ cell effector

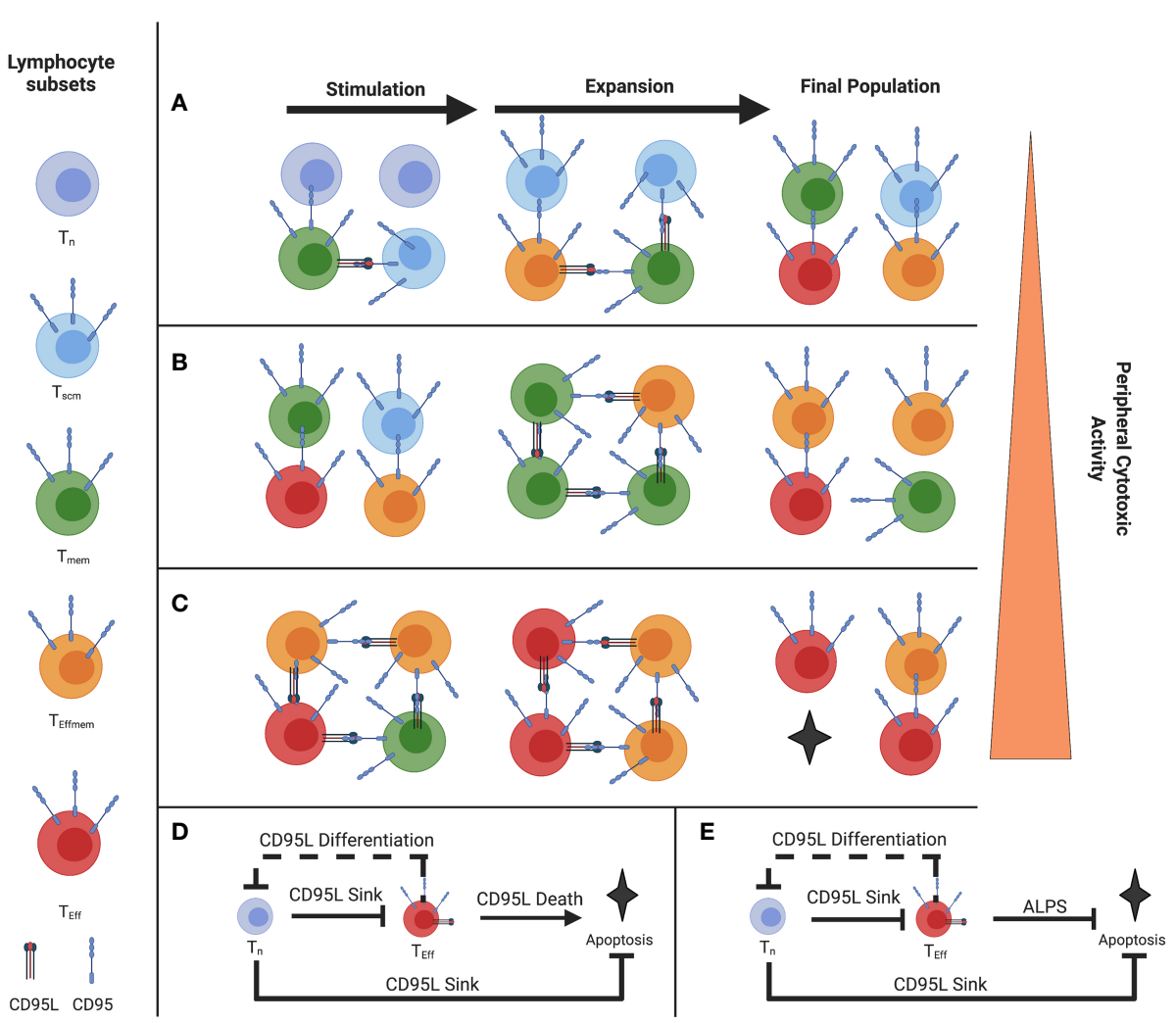

FIGURE 1 | Illustration of the Paracrine Fas/FasL differentiation and death system (A) Stimulation of a naive-rich pool of T-cells corresponding to a youthful repertoire (B) Stimulation of a more differentiated pool of T-cells (C) Stimulation of a pool of T-cells with few Tn, where the population will reach cytotoxic function more exuberantly (D) Proposed coherent type 2 Feed-Forward Loop of Fas-mediated differentiation and death (solid line), with a negative feedback loop on naive T cells from effector T cells (E) FFL error from coherent type 2 to incoherent type 2 in ALPS and the murine model Fas C194V due to a defect in CD95-mediated Apoptosis but not CD95-mediated differentiation. (Figure adapted with permission from Leonardi and Proenca, 2020). 
differentiation $(15,16)$. Indeed, many peripherally-infiltrating lymphocytes in infection are short-lived and are not accompanied by Naive and Tscm cells that could prevent their full effector function (17). Furthermore, immune privileged sites like the eye exploit this susceptibility by expressing FasL to quickly delete wayward $\mathrm{T}$ cells $(18,19)$. Therefore, this Terminal portion of the Fas-FasL feed-forward loop is an essential component of immune tolerance and $\mathrm{T}$ cell control $(20,21)$.

The specific kinetic and dynamic mirrors a type 2 coherent Feed Forward Loop where disturbances are corrected for and responses are accelerated and then quite literally, terminated, by apoptosis $(2,3,5,6)$. Prior evidence includes 1$)$ how naive CD8 T-cells act as a "sink", withholding differentiation and cytotoxic function in memory CD8 T-cells (5), and 2) how acute T-T interactions can prime Tumor-specific effector $\mathrm{T}$ cells to more exuberantly act against tumor (22).

The significance of this Feed-Forward Loop is shown by the protective effect of Tn CD8+ cells in Covid-19 (23), which reconciles the highly discrepant outcomes seen between children (low mortality) $(24,25)$ and elderly adults (high mortality) $(26,27)$. A Fas-mediated role of excessive T-cell death in severe cases has recently become more evident as well, lending credibility to the earlier proposal about its role in apoptosis $(12,28)$.

Indeed, André et al. propose blocking Fas-mediated death via a pan caspase inhibitor Q-VD (28). Finally, given the differentiation and depreciation of the Tn pool from infection likely due to the overshooting T-cell stimulation from SARSCov-2's cryptic (29) accumulation of superantigenic biomass (12, 30,31 ), $\mathrm{T}$ cell activation via complement (32), and bystander activation (33), we can use the model to anticipate the possibility of worsening disease upon reinfection in cases where there is not adequate early control and a highly differentiated $\mathrm{T}$ cell repertoire (34). This does not mean all reinfections will be worse, rather that they will be worse when the parameters of this feed-forward model are met.

\section{DISCUSSION}

\section{What Explains Heightened Severity in the Aged and Mild IIIness in the Youth?}

There is a dire need to explain the wide gamut of immune dysfunction in Covid-19 between mild and severe disease (35). Here, we incorporate a major correlation of Covid- 1 severity; the proportion of CD8+ naïve $\mathrm{T}$ cells $(12,23,36)$. As described by Moderbacher, et al., a higher proportion of these cells is protective in Covid-19. Indeed, much of the pathology in Covid-19 is T cell driven, and it would be useful to incorporate these observations into a system/model that reconciles them. We previously described how Tn and Tscm can act as 'sinks' for a differentiation and death signal $(12,37)$. de Candia et al. proposed that naive repertoires exert better control by virtue of greater TCR repertoire diversity which historically is associated with lower CD4 and CD8 T cell activation (38). however no model reconciles 1) the low Case Fatality Rate (CFR) seen in children $(24,25) ; 2)$ the high CFR seen in the elderly (39); 3 ) cases of more severe reinfection $(40) ; 4)$ the efficacy of steroids, which cause a rapid reduction in CD8+ T-cells, and suppress Fas and FasL in T-cells (41-45); 5) the efficacy of anti GM-CSF (46, 47), which downregulates Fas expression on T-cells (48); and the high degree of Fas-mediated $\mathrm{T}$ cell apoptosis which characterizes severe Covid-19 (28).

\section{Proposing A Fas/Akt Differentiation and Death Feed-Forward Loop}

We previously described a system where, under costimulation, Tscm expressed CD95 and acted as a 'sink' for CD95L expressed by Teff, Tem, and Tcm $(12,37)$. This CD95L expression induces differentiation in proximal cells where CD95 is ligated, except in terminally-differentiated cells where it induces death (5). This effect can be blocked with CD178 blockade or AKT inhibition without affecting $\mathrm{T}$ cell proliferation $(5,12)$. Based on the differentiation status/proportion of $\mathrm{Tn}$ of the $\mathrm{T}$ cell population undergoing stimulation, we can gauge how prone to exuberant effector function the resultant pool of T cells will behave, with higher proportion of Tn being protective as described by Moderbacher et al. (23) (Figures 1A-C) As FasL is expressed later in the stages of $\mathrm{T}$ cell differentiation, there is an epigenetic controller regulating its expression as part of a canonically developmental type 2 coherent feed forward loop $(2,3,5)$ (Figure 1D). Furthermore, there is negative feedback in the system where Tem push the differentiation of CD95-expressing Tn (or Tscm) which reduces the dampening effect of the Tscm by reducing their numbers and promoting their acquisition of CD95L. This negative feedback is prototypically implemented alongside feed-forward loops $(4,49)$. The FFL ends when CD8+ $\mathrm{T}$ cells that have reached terminal differentiation undergo apoptosis and are removed from the pool. Disturbances in this terminal element of coherent FFL control are exemplified in ALPS, where the apoptotic function of Fas is ablated but the terminal effector differentiation is maintained (50) (Figure 1E). Indeed, we see the consequence of what is ideally, a type 2 coherent FFL mutagenically switched to a type 2 incoherent FFL which loses the termination of the differentiation effect via apoptosis, as described by Mangon and Alon (2, 49). The difference in whether a FFL is coherent vs. incoherent depends on the sign (positive or negative, respectively) of the output (2). For example, in the condition ALPS Fas- mediated death is disrupted, so the FFL drives to terminal effector differentiation without apoptosis, reversing the sign of the outcome $(2,21)$. As such, we can contextualize the autoimmune toxicity to peripheral tissues and lymphoproliferation and see the physiological utility of the coherent FFL as opposed to an incoherent FFL in the Fas/ Akt Differentiation and Death feed-forward system (2, 5, 12, 37, 50, 51).

\section{Perilous "Recall": Depletion Dependent Enhancement}

In SARS Cov-2 infection, peripheral blood CD8+ phenotypes exhibit a significant reduction in the proportion of $\mathrm{Tn}$ and an 
increase of Teff (52). In a single cell analysis of T cell memory following infection, Adamo et al. observe that severe cases of Covid-19 are marked by a CD8+ T cell effector population they assume is induced by bystander activation, and mild cases marked by a memory phenotype (53). Cohen et al. examined the differences in T cell induction of IFN- $\gamma$ and found increased age was associated with higher $\mathrm{T}$-cell activation and concluded that reduced the T-cell activation in children may be responsible for milder Covid-19 (25). Previously, we described a model of Tcell driven Covid-19 severity incorporating the finding of Moderbacher, et al., where an increased proportion of CD8+ Tn had a protective effect $(12,23,37)$. In the model, we showed $\mathrm{T}$ cells with a higher proportion of Fas expression would differentiate due to a Fas-potentiated non-apoptotic Akt signal, thereby causing the exuberant $\mathrm{T}$ cell effector function seen in severe cases (12). Given the possible frequency of Covid-19 reinfection and rechallenge, the model can be updated to incorporate $\mathrm{T}$ cell differentiation and effector function conferred by reinfection. Based upon data showing a retraction of the Tn repertoire following infection by Townsend et al, and Phetsouphanh et al, we can speculate regarding a possible " $\mathrm{T}$ cell depletion dependent enhancement" as the stimulated repertoire (which includes the $\mathrm{T}$ cells specific to SARS-Cov-2 epitopes, those activated by a bystander effect, and those also stimulated superantigenically and by complement) has lost a proportion of its $\mathrm{Tn}$ and is thereby able to quickly differentiate into $\mathrm{T}$ cell Effectors since there is no CD95L sink that the CD95 expression on Tn and Tscm offer $(30-32,54)$. This effect would be more evident in the aged 60+, who have significant reductions in CD8 + Tn proportions following SARS Cov- 2 infection, due to the bystander, complement, and superantigen-induced excessive stimulation $(30-32,34)$. Of course, primed T-cells such as those from vaccination are capable of exerting earlier control of infection (55); and indeed, early CD8 bystander activation is associated with better control of infection (33), so we anticipate a degree of protection conferred from vaccination when the individual has a paucity of naïve $\mathrm{T}$ cells, such as in Figure 1C. We must note, however, infection with SARS-CoV-2 represents a challenge for the CD8+ compartment given its immune evasion, like Major Histocompatibility Complex 1 (MHC 1) downregulation (29). In cases where early control is not accomplished, $\mathrm{T}$ cell memory could contribute to an overexuberant response $(12,37,38)$. Indeed, exuberant CD8+ T-cell mediated pathology has been documented in infections like RSV and SARS-CoV-2 alike $(32,56,57)$. Memory CD8+ responses have been shown to exert immunopathology and severe disease in murine models of RSV (56).

Additionally, this model suggests a pathogenic role in FasLmediated $\mathrm{T}$ cell differentiation in the development of Type 1 diabetes, as shown in the NOD mice model by Xiao, et al. (58, 59) In NOD mice, CD8+ T-cells have been shown to exert $\beta$ cell destruction, which can be abrogated with FasL blockade, which would reduce CD8+ effector differentiation and function $(11,58,59)$. This pathway is growing in relevance considering the risk for newly diagnosed autoimmune diabetes (Type 1) following SARS-Cov-2 infection, and consideration of this model and the nonspecific T-cell activation and differentiation observed in COVID-19 would proffer mechanism in part (60).

\section{Pride Goeth Before The Fall: The Utility of Apoptosis Following Differentiation}

On T-cells, the CD95 receptor potentiates a differentiation signal via AKT until the $\mathrm{T}$-cell reaches terminal differentiation, whereby CD95 engagement induces apoptosis $(11,50)$. Evolutionarily, programming apoptosis into the same system of effector differentiation by the adaptive immune system is an elegant means of assuring self-limiting effector $\mathrm{T}$ cell responses. Where CD95-mediated death does not occur, such as in cases of ALPS, T-cell effector populations may accumulate, manifesting in autoimmunity and lymphoproliferation $(61,62)$.

\section{"Driven" by Danger, Effector T Cells Cut the Brake Lines and Step on the Gas}

The feed-forward model proposed here represents a quorumlike $\mathrm{T}$ cell dynamic in activated states (63). To revisit our analogy, naïve T cells are like the 'brakes' for a high response whereby they 'absorb' CD95L. In situations with persistent and broad activation of naïve $\mathrm{T}$ cells they would be subjected to FasL expressing cells upon arrival to the lymph nodes and differentiated by those means. Long Covid's paucity of naïve $\mathrm{T}$ cells would fit this dynamic (54). As shown in the dotted negative feedback line in Figure 1D, FasL-expressing effectors can precociously differentiate naïve $\mathrm{T}$ cells, like "cutting the brakes" before a turn $(12,37)$. Such negative feedback loops are canonically found alongside feed-forward loops $(4,49)$. If there was a persistent or evasive antigenic reservoir capable of evading adaptive immunity and continually stimulating $\mathrm{T}$ cells it could explain the persistent elevation of Effectors and depletion of Tn seen in some cases of Long Covid (54). Persistent activation could hasten $\mathrm{T}$ cell differentiation and manifest in a naïve depletion, effectively manifesting as "cutting the brakes" in this model where naïve T cells dampen exuberant responses. A persistent command on the feed-forward controller could deplete the naive $\mathrm{T}$ cell subset by this mechanism, if the stimulation is broad enough. This mechanism may also, in part, describe an insidious lymphocyte depletion where there is chronic activation and loss of $\mathrm{T}$ populations in chronic infections with substantial bystander activation (64).

\section{CONCLUSION}

T-cell differentiation and acquisition of effector function is accomplished via Feed-forward control. In Covid-19, there is nonspecific and possibly bystander cytotoxic CD8+ T-cell activation which may be a double-edged sword, exerting damage to tissues and vital organs like the lung and pancreas $(14,30-32,52,53,60)$. The FFL proposed here gives a 
mechanism for both the exuberant T-cell response observed in severe cases and the protective effect of $\operatorname{Tn}(12,23,32,37)$. It also anticipates the consequences of a diminishing pool of Tn if we are to consider the documented reduction of the naive $\mathrm{T}$ cell repertoire in SARS Cov-2 convalescence $(34,52)$, which may be induced by the superantigenic nature of infection and the bystander activation of $\mathrm{T}$ cells $(30,32)$. If this dynamic is correct and appreciable, COVID-19 reinfections may manifest more severe disease as $\mathrm{T}$ cell repertoires age and $\mathrm{Tn}$ reduce in frequency, manifesting in an individual and demographic level.

\section{REFERENCES}

1. Houk JC. Control Strategies in Physiological Systems. FASEB J (1988) 2 (2):97-107. doi: 10.1096/fasebj.2.2.3277888

2. Mangan S, Alon U. Structure and Function of the Feed-Forward Loop Network Motif. Proc Natl Acad Sci U S A (2003) 100(21):11980. doi: $10.1073 /$ pnas.2133841100

3. Alon U. Network Motifs: Theory and Experimental Approaches. Nat Rev Genet (2007) 8(6):450-61. doi: 10.1038/nrg2102

4. Reeves GT. The Engineering Principles of Combining a Transcriptional Incoherent Feedforward Loop With Negative Feedback. J Biol Eng (2019) 13(1):62. doi: 10.1186/s13036-019-0190-3

5. Klebanoff CA, Scott CD, Leonardi AJ, Yamamoto TN, Cruz AC, Ouyang C, et al. Memory T Cell-Driven Differentiation of Naive Cells Impairs Adoptive Immunotherapy. J Clin Invest (2016) 126(1):318-34. doi: 10.1172/JCI81217

6. Rahman A, Tiwari A, Narula J, Hickling T. Importance of Feedback and Feedforward Loops to Adaptive Immune Response Modeling. CPT Pharmacomet Syst Pharmacol (2018) 7(10):621-8. doi: 10.1002/psp4.12352

7. Brandes M, Klauschen F, Kuchen S, Germain RN. A Systems Analysis Identifies a Feed-Forward Inflammatory Circuit Leading to Lethal Influenza Infection. Cell (2013) 154(1):197. doi: 10.1016/j.cell.2013.06.013

8. Rahman A, Haugh JM. Kinetic Modeling and Analysis of the Akt/Mechanistic Target of Rapamycin Complex 1 (Mtorc1) Signaling Axis Reveals Cooperative, Feedforward Regulation. J Biol Chem (2017) 292(7):2866. doi: 10.1074/jbc.M116.761205

9. Kaech SM, Cui W. Transcriptional Control of Effector and Memory CD8+ T Cell Differentiation. Nat Rev Immunol (2012) 12(11):749. doi: 10.1038/ nri3307

10. Crompton JG, Sukumar M, Roychoudhuri R, Clever D, Gros A, Eil RL, et al. Akt Inhibition Enhances Expansion of Potent Tumor-Specific Lymphocytes With Memory Cell Characteristics. Cancer Res (2015) 75(2):296-305. doi: 10.1158/0008-5472.CAN-14-2277

11. Klebanoff CA, Crompton JG, Leonardi AJ, Yamamoto TN, Chandran SS, Eil RL, et al. Inhibition of AKT Signaling Uncouples T Cell Differentiation From Expansion for Receptor-Engineered Adoptive Immunotherapy. JCI Insight (2017) 2(23):e95103. doi: 10.1172/jci.insight.95103

12. Leonardi AJ, Proenca RB. Akt-Fas to Quell Aberrant T Cell Differentiation and Apoptosis in Covid-19. Front Immunol (2020) 11:600405. doi: 10.3389/ fimmu.2020.600405

13. O'Connell J. Fas Ligand and the Fate of Antitumour Cytotoxic T Lymphocytes. Immunology (2002) 105(3):263. doi: 10.1046/j.13652567.2002.01379.x

14. Galeano Niño JL, Pageon SV, Tay SS, Colakoglu F, Kempe D, Hywood J, et al. Cytotoxic T Cells Swarm by Homotypic Chemokine Signalling. Rath S, Ed. eLife (2020) 9:e56554. doi: 10.7554/eLife.56554

15. Ding Y, Wang H, Shen H, Li Z, Geng J, Han H, et al. The Clinical Pathology of Severe Acute Respiratory Syndrome (SARS): A Report From China. J Pathol (2003) 200(3):282-9. doi: 10.1002/path.1440

16. Merad M, Martin JC. Pathological Inflammation in Patients With COVID-19: A Key Role for Monocytes and Macrophages. Nat Rev Immunol (2020) 20 (6):355-62. doi: 10.1038/s41577-020-0331-4

17. Sathaliyawala T, Kubota M, Yudanin N, Turner D, Camp P, Thome JJC, et al. Distribution and Compartmentalization of Human Circulating and Tissue-

\section{AUTHOR CONTRIBUTIONS}

AL contrived the model and co-wrote the manuscript with CA, $\mathrm{AH}$, and RP. All authors contributed to the article and approved the submitted version.

\section{ACKNOWLEDGMENTS}

Figure made with BioRender.com.

Resident Memory T Cell Subsets. Immunity (2013) 38(1):187-97. doi: 10.1016/j.immuni.2012.09.020

18. Ferguson TA, Green DR. Fas-Ligand and Immune Privilege: The Eyes Have it. Cell Death Differ (2001) 8(7):771-2. doi: 10.1038/sj.cdd.4400891

19. Griffith TS, Brunner T, Fletcher SM, Green DR, Ferguson TA. Fas LigandInduced Apoptosis as a Mechanism of Immune Privilege. Science (1995) 270 (5239):1189-92. doi: 10.1126/science.270.5239.1189

20. Stuart PM, Griffith TS, Usui N, Pepose J, Yu X, Ferguson TA. CD95 Ligand (FasL)-Induced Apoptosis is Necessary for Corneal Allograft Survival. J Clin Invest (1997) 99(3):396-402. doi: 10.1172/JCI119173

21. Viorritto ICB, Nikolov NP, Siegel RM. Autoimmunity Versus Tolerance: Can Dying Cells Tip the Balance? Clin Immunol Orlando Fla (2007) 122(2):12534. doi: 10.1016/j.clim.2006.07.012

22. Zhou J, Bethune MT, Malkova N, Sutherland AM, Comin-Anduix B, Su Y, et al. A Kinetic Investigation of Interacting, Stimulated T Cells Identifies Conditions for Rapid Functional Enhancement, Minimal Phenotype Differentiation, and Improved Adoptive Cell Transfer Tumor Eradication. PloS One (2018) 13(1):e0191634. doi: 10.1371/journal.pone.0191634

23. Moderbacher CR, Ramirez SI, Dan JM, Grifoni A, Hastie KM, Weiskopf D, et al. Antigen-Specific Adaptive Immunity to SARS-CoV-2 in Acute COVID19 and Associations With Age and Disease Severity. Cell (2020) 183(4):996. doi: 10.1016/j.cell.2020.09.038

24. Zimmermann P, Curtis N. Why is COVID-19 Less Severe in Children? A Review of the Proposed Mechanisms Underlying the Age-Related Difference in Severity of SARS-CoV-2 Infections. Arch Dis Child (2021) 106(5):429-39. doi: 10.1136/archdischild-2020-320338

25. Cohen CA, Li APY, Hachim A, Hui DSC, Kwan MYW, Tsang OTY, et al. SARS-CoV-2 Specific T Cell Responses are Lower in Children and Increase With Age and Time After Infection. Nat Commun (2021) 12:4678. doi: 10.1038/s41467-021-24938-4

26. Levin AT, Hanage WP, Owusu-Boaitey N, Cochran KB, Walsh SP, Meyerowitz-Katz G. Assessing the Age Specificity of Infection Fatality Rates for COVID-19: Systematic Review, Meta-Analysis, and Public Policy Implications. Eur J Epidemiol (2020) 35(12):1123. doi: 10.1007/s10654-02000698-1

27. Pereira MFB, Litvinov N, Farhat SCL, Eisencraft AP, Gibelli MABC, de Carvalho WB, et al. Severe Clinical Spectrum With High Mortality in Pediatric Patients With COVID-19 and Multisystem Inflammatory Syndrome. Clin Sao Paulo Braz (2020) 75:e2209. doi: 10.6061/clinics/2020/ e2209

28. André S, Picard M, Cezar R, Roux-Dalvai F, Alleaume-Butaux A, Soundaramourty C, et al. T Cell Apoptosis Characterizes Severe Covid-19 Disease. Cell Death Differ (2022) 22:1-14. doi: 10.1038/ s41418-022-00936-x

29. Zhang Y, Chen Y, Li Y, Huang F, Luo B, Yuan Y, et al. The ORF8 Protein of SARS-CoV-2 Mediates Immune Evasion Through Down-Regulating MHC-1. Proc Natl Acad Sci (2021) 118(23):e2024202118. doi: 10.1073/ pnas. 2024202118

30. Cheng MH, Zhang S, Porritt RA, Rivas MN, Paschold L, Willscher E, et al. Superantigenic Character of an Insert Unique to SARS-CoV-2 Spike Supported by Skewed TCR Repertoire in Patients With Hyperinflammation. Proc Natl Acad Sci (2020) 117(41):25254-62. doi: $10.1073 /$ pnas.2010722117 
31. Yonker LM, Gilboa T, Ogata AF, Senussi Y, Lazarovits R, Boribong BP, et al. Multisystem Inflammatory Syndrome in Children is Driven by ZonulinDependent Loss of Gut Mucosal Barrier. J Clin Invest (2021) 131(14): e149633. doi: 10.1172/JCI149633

32. Georg P, Astaburuaga-García R, Bonaguro L, Brumhard S, Michalick L, Lippert LJ, et al. Complement Activation Induces Excessive T Cell Cytotoxicity in Severe COVID-19. Cell (2022) 185(3):493-512.e25. doi: 10.1016/j.cell.2021.12.040

33. Bergamaschi L, Mescia F, Turner L, Hanson AL, Kotagiri P, Dunmore BJ, et al. Longitudinal Analysis Reveals That Delayed Bystander CD8+ T Cell Activation and Early Immune Pathology Distinguish Severe COVID-19 From Mild Disease. Immunity (2021) 54(6):1257-1275.e8. doi: 10.1016/ j.immuni.2021.05.010

34. Townsend L, Dyer AH, Naughton A, Kiersey R, Holden D, Gardiner M, et al. Longitudinal Analysis of COVID-19 Patients Shows Age-Associated T Cell Changes Independent of Ongoing Ill-Health. Front Immunol (2021) 12:676932. doi: 10.3389/fimmu.2021.676932

35. Brodin P. SARS-CoV-2 Infections in Children: Understanding Diverse Outcomes. Immunity (2022) 55(2):201-9. doi: 10.1016/j.immuni.2022.01.014

36. Betjes MGH. Uremia-Associated Immunological Aging and Severity of COVID-19 Infection. Front Med (2021) 8:675573. doi: 10.3389/ fmed.2021.675573

37. Leonardi AJ. Akt Fas to Quell Aberrant T Cell Differentiation and Death in Covid-19. Charlottesville, VA: OSF Preprints (2020). doi: 10.31219/osf.io/ 2egsm.

38. de Candia P, Prattichizzo F, Garavelli S, Matarese G. T Cells: Warriors of SARS-CoV-2 Infection. Trends Immunol (2021) 42(1):18-30. doi: 10.1016/ j.it.2020.11.002

39. Kang SJ, Jung SI. Age-Related Morbidity and Mortality Among Patients With COVID-19. Infect Chemother (2020) 52(2):154. doi: 10.3947/ ic.2020.52.2.154

40. Slezak J, Bruxvoort K, Fischer H, Broder B, Ackerson B, Tartof S. Rate and Severity of Suspected SARS-Cov-2 Reinfection in a Cohort of PCR-Positive COVID-19 Patients. Clin Microbiol Infect (2021) 27(12):1860. doi: 10.1016/ j.cmi.2021.07.030

41. Li H, Yan B, Gao R, Ren J, Yang J. Effectiveness of Corticosteroids to Treat Severe COVID-19: A Systematic Review and Meta-Analysis of Prospective Studies. Int Immunopharmacol (2021) 100:108121. doi: 10.1016/ j.intimp.2021.108121

42. Ma S, Xu C, Liu S, Sun X, Li R, Mao M, et al. Efficacy and Safety of Systematic Corticosteroids Among Severe COVID-19 Patients: A Systematic Review and Meta-Analysis of Randomized Controlled Trials. Signal Transduct Target Ther (2021) 6(1):1-7. doi: 10.1038/s41392-021-00521-7

43. Bahr EC, Yorty JL. Rapid Decrease in CD8 T Cells Following Treatment of Mice With Exogenous Corticosterone. BIOS (2013) 84(3):148-57. doi: 10.1893/0005-3155-84.3.148

44. Kumar D, Sehrawat S. Divergent Effects of a Transient Corticosteroid Therapy on Virus-Specific Quiescent and Effector CD8+ T Cells. Front Immunol (2019) 10:1521. doi: 10.3389/fimmu.2019.01521

45. Davis TE, Kis-Toth K, Szanto A, Tsokos GC. Glucocorticoids Suppress T Cell Function by Upregulating microRNA 98. Arthritis Rheumatol (2013) 65 (7):1882. doi: $10.1002 /$ art.37966

46. Gottlieb RL, Lang FM, Criner GJ, Mathews KS, Wang TS, Rice TW, et al. Abstract 14310: Anti-GM-CSF Monoclonal Antibody Gimsilumab Improved Ventilator-Free Survival, Decreased Hospitalization Length, and Prevented NT-proBNP Rise in Invasively Ventilated Patients With Hyperinflammatory COVID-19 Pneumonia: A Subgroup Analysis From the Breathe Trial Suggests Neurohormonal Role for GM-CSF Inhibition. Circulation (2021) 144 (Suppl_1):A14310-0. doi: 10.1161/circ.144.suppl_1.14310

47. Temesgen Z, Assi M, Shweta FNU, Vergidis P, Rizza SA, Bauer PR, et al. GMCSF Neutralization With Lenzilumab in Severe COVID-19 Pneumonia: A Case-Cohort Study. Mayo Clin Proc (2020) 95(11):2382. doi: 10.1016/ j.mayocp.2020.08.038

48. Cox MJ, Kuhlmann CJ, Sterner RM, Sakemura R, Sinha S, Mwangi R, et al. Improved Anti-Tumor Response of Chimeric Antigen Receptor T Cell (CART) Therapy After GM-CSF Inhibition Is Mechanistically Supported By a Novel Direct Interaction of GM-CSF With Activated Carts. Blood (2019) 134 (Supplement_1):3868. doi: 10.1182/blood-2019-129349
49. Mokhatab S, Poe WA. Chapter 14 - Process Control Fundamentals. In: S Mokhatab, WA Poe, editors. Handbook of Natural Gas Transmission and Processing, 2nd ed. Waltham, MA: Gulf Professional Publishing (2012). p. 473-509. doi: 10.1016/B978-0-12-386914-2.00014-5

50. Cruz AC, Ramaswamy M, Ouyang C, Ramaswamy M, Ouyang C, Klebanoff CA, et al. Fas/CD95 Prevents Autoimmunity Independently of Lipid Raft Localization and Efficient Apoptosis Induction. Nat Commun (2016) 7:13895. doi: 10.1038/ncomms 13895

51. López-Nevado M, González-Granado LI, Ruiz-García R, Pleguezuelo D, Cabrera-Marante O, Salmón N, et al. Primary Immune Regulatory Disorders With an Autoimmune Lymphoproliferative Syndrome-Like Phenotype: Immunologic Evaluation, Early Diagnosis and Management. Front Immunol (2021) 12:671755. doi: 10.3389/fimmu.2021.671755

52. Biasi SD, Meschiari M, Gibellini L, Bellinazzi C, Borella R, Fidanza L, et al. Marked T Cell Activation, Senescence, Exhaustion and Skewing Towards TH17 in Patients With COVID-19 Pneumonia. Nat Commun (2020) 11:3434. doi: 10.1038/s41467-020-17292-4

53. Adamo S, Michler J, Zurbuchen Y, Cervia C, Taeschler P, Raeber ME, et al. Signature of Long-Lived Memory CD8+ T Cells in Acute SARS-CoV-2 Infection. Nature (2021) 602:148-55. doi: 10.1038/s41586-021-04280-x

54. Phetsouphanh C, Darley DR, Wilson DB, Howe A, Munier CML, Patel SK, et al. Immunological Dysfunction Persists for 8 Months Following Initial Mild-to-Moderate SARS-CoV-2 Infection. Nat Immunol (2022) 23(2):210-6. doi: 10.1038/s41590-021-01113-x

55. Snell LM, MacLeod BL, Law JC, Osokine I, Elsaesser HJ, Hezaveh K, et al. CD8 + T Cell Priming in Established Chronic Viral Infection Preferentially Directs Differentiation of Memory-Like Cells for Sustained Immunity. Immunity (2018) 49(4):678-694.e5. doi: 10.1016/j.immuni.2018.08.002

56. Schmidt ME, Knudson CJ, Hartwig SM, Pewe LL, Meyerholz DK, Langlois RA, et al. Memory CD8 T Cells Mediate Severe Immunopathology Following Respiratory Syncytial Virus Infection. PloS Pathog (2018) 14(1):e1006810. doi: 10.1371/journal.ppat.1006810

57. Cheon IS, Li C, Son YM, Goplen NP, Wu Y, Cassmann T, et al. Immune Signatures Underlying Post-Acute COVID-19 Lung Sequelae. Sci Immunol (2021) 6(65):eabk1741. doi: 10.1126/sciimmunol.abk1741

58. Xiao Z, Mohamood AS, Uddin S, Gutfreund R, Nakata C, Marshall A, et al. Inhibition of Fas Ligand in NOD Mice Unmasks a Protective Role for IL-10 Against Insulitis Development. Am J Pathol (2011) 179(2):725. doi: 10.1016/ j.ajpath.2011.04.016

59. Amrani A, Verdaguer J, Anderson B, Utsugi T, Bou S, Santamaria P. PerforinIndependent $\beta$-Cell Destruction by Diabetogenic CD8+ T Lymphocytes in Transgenic Nonobese Diabetic Mice. J Clin Invest (1999) 103(8):1201. doi: $10.1172 /$ JCI6266

60. Barrett CE. Risk for Newly Diagnosed Diabetes 30 Days After SARS-CoV-2 Infection Among Persons Aged 18 Years - United States, March 1, 2020-June 28, 2021. MMWR Morb Mortal Wkly Rep (2022) 71:59-65. doi: 10.15585/ mmwr.mm7102e2

61. Mazerolles F, Stolzenberg MC, Pelle O, Picard C, Neven B, Fischer A, et al. Autoimmune Lymphoproliferative Syndrome-FAS Patients Have an Abnormal Regulatory T Cell (Treg) Phenotype But Display Normal Natural TregSuppressive Function on T Cell Proliferation. Front Immunol (2018) 9:718. doi: $10.3389 /$ fimmu.2018.00718

62. Rieux-Laucat F. [Autoimmune Lymphoproliferative Syndrome: An Inherited or a Somatic Defect of Apoptosis]. Med Sci MS (2006) 22(6-7):645-50. doi: $10.1051 /$ medsci/20062267645

63. Al-Yassin GA, Bretscher PA. Does T Cell Activation Require a Quorum of Lymphocytes? J Immunol (2018) 201(10):2855-61. doi: 10.4049/jimmunol.1800805

64. Roederer M, Dubs JG, Anderson MT, Raju PA, Herzenberg LA, Herzenberg LA. CD8 Naive T Cell Counts Decrease Progressively in HIV-Infected Adults. J Clin Invest (1995) 95(5):2061-6. doi: 10.1172/JCI117892

Conflict of Interest: The authors declare that the research was conducted in the absence of any commercial or financial relationships that could be construed as a potential conflict of interest.

Publisher's Note: All claims expressed in this article are solely those of the authors and do not necessarily represent those of their affiliated organizations, or those of the publisher, the editors and the reviewers. Any product that may be evaluated in 
this article, or claim that may be made by its manufacturer, is not guaranteed or endorsed by the publisher.

Copyright $\odot 2022$ Leonardi, Argyropoulos, Hamdy and Proenca. This is an openaccess article distributed under the terms of the Creative Commons Attribution
License (CC BY). The use, distribution or reproduction in other forums is permitted, provided the original author(s) and the copyright owner(s) are credited and that the original publication in this journal is cited, in accordance with accepted academic practice. No use, distribution or reproduction is permitted which does not comply with these terms. 